\title{
Experimental and numerical investigations of primary flow patterns and mixing in laboratory meandering channel
}

Sung Won Park and Jungkyu Ahn*

\author{
*Correspondence: ahnjk@inu.ac.kr \\ Department of Civil and \\ Environmental Engineering, Incheon \\ National University, Incheon, South \\ Korea
}

\begin{abstract}
Considering fundamental hydraulics, fluid dynamics, and experimental analysis should be analyzed simultaneously with mathematical methods due to the effects of hydraulic properties such as meandering form, sediment, and so on. In this research, to reveal the effects of hydraulic characteristics and longitudinal and transverse coefficients based on the two-dimensional advection-dispersion equation, a laboratory experimental channel has been conducted and analyzed. Additionally, results of experiments have been compared with horizontal two dimensional distributions of flow velocity and concentration fields with respect to the water depth and inlet discharge using two-dimensional depth-averaged numerical models based on FEM (Finite Element Method). SMS and RAMS have been applied with the same experimental conditions and compared. From the analysis of velocity profiles, primary and secondary flows have been visualized. Also the result of pollutant clouds illustrated from the results of tracer tests with an instantaneous and centered injection of solute transport, separation, superposition and stagnation could be deduced outwards of two meandering sections. And same types of characteristics of velocity and pollutant transport could be defined with two-dimensional numerical models.

Keywords: Meandering, Two-dimensional advection-dispersion equation, Longitudinal and transverse coefficients, Two-dimensional depth averaged numerical models, Velocity profiles, Pollutant transport
\end{abstract}

\section{Introduction}

Three major types of fluvial geomorphological characteristics were classified with straight, meandering and braided. Meandering pattern has various characteristics of flow and geomorphology in the natural rivers and streams. Whole inflows and spreading out of various toxic pollutants in inland and coastal waters such as rivers, streams, and estuaries have been happened in accordance with continuous population growth and drastic industrial development. They have also threatened the environmental balance of human life. It is therefore a sustainable management of flow patterns and spatial water quality should be continued with a consideration of topographical characteristics. Natural streams and rivers generally have bends, sandbars, side pockets, pools, riffles, bridge piers, man-made revetments, and especially meandering form. Essentially meander is a type of bed

(c) The Author(s). 2019 Open Access This article is distributed under the terms of the Creative Commons Attribution 4.0 International License (http://creativecommons.org/licenses/by/4.0/), which permits unrestricted use, distribution, and reproduction in any medium, provided you give appropriate credit to the original author(s) and the source, provide a link to the Creative Commons license, and indicate if changes were made. 
forms which transport and hydraulics within a channel cooperate to generate and this form is related to a geometry which is generated and maintained by a 'spiral' motion of the river through the bends (Fig. 1).

It is necessary to maintain and control water pollution problems with accurate researches and continuous efforts to predict losses and damages from them using numerical analysis verified with experimental researches or field tests. To simulate complex flow and pollutant transport in meandering channel, a three-dimensional hydrodynamic model is required. However, for a computational and laboratory limit, a two-dimensional model can be used over three-dimensional model, greatly reducing efforts and expenses. An appropriate choice of dimensional methods needs to be classified with considering regional conditions of pollutant mixing (Fig. 2). Additionally to reveal hydrodynamic characteristics in intermediate field, experimental analysis should be considered with two-dimensional method.

In this research, flow and pollutant mixing have been analyzed based on experimental data with set of longitudinal and transverse dispersion coefficients evaluated with using various theoretical and empirical methods. A theoretical approach which in another methodology for evaluating the transverse dispersion coefficient in cases of having no concentration data was proposed, for the first time, by using the transverse velocity equation of Rozovskii (1961) and also suggested flow features to the transverse dispersion coefficient considered bend effects. Chang (1971) conducted laboratory experiments with the S-curved channel to obtain the transverse dispersion coefficient considering the secondary flow effects. Recently, Boxall and Guymer (2003) suggested new theoretical equation. Summary of assumptions and results of previous studies which have been involved with this study have been represented in Table 1.

Numerical approaches have been developed for describing circulation phenomena and the solute transport in the meandering open channel flows. McGuirk

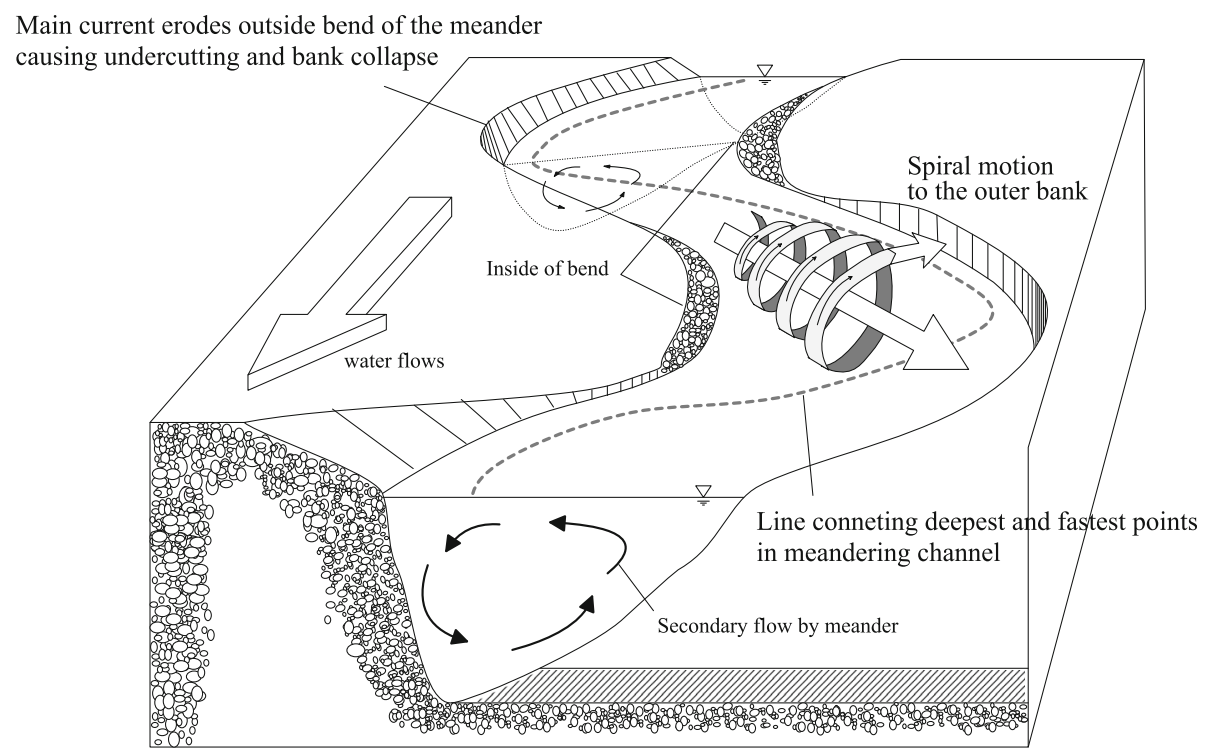

Fig. 1 Physical processes in typical meandering channel 


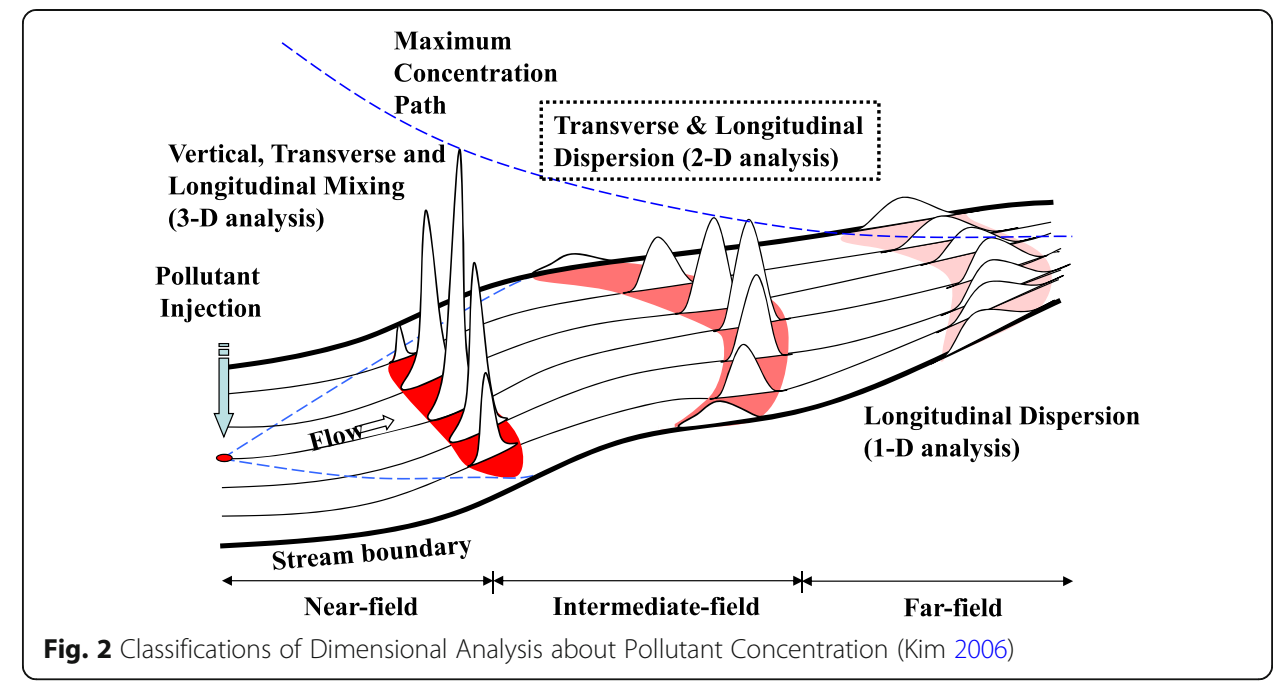

and Rodi (1978) developed a depth-averaged model for the near field calculations of the flow and concentration distribution by side discharges of the pollutant into open-channel flow. Duan (2004) has derived the dispersion term for the depth-averaged 2D model in Cartesian coordinates and used the Schmidt number as a calibration parameter to simulate mass dispersion in meandering channels. The model by Duan (2004) was applied to the experiments of Chang (1971) to test the capability of the model to simulate mass transport in meandering channels.

\section{Experimental analysis}

\section{Governing equation}

The three-dimensional Fickian diffusion equation under a non-buoyant tracer being transported in an unsaturated incompressible laminar flow in the Cartesian

Table 1 Experimental Researches about Mixing in Channels

\begin{tabular}{lll}
\hline Researcher & Channel & Results \\
\hline Elder (1959) & Straight & $e_{y} / H U_{*}=0.23$ \\
Fischer (1969) & Meander & Theoretical form Derived \\
Chang (1971) & Meander & Developed \\
Miller \& Richardson (1974) & Straight & $D_{L} / e_{y}>100$ \\
Krishnappan \& Lau (1977) & Meander & $0.222<D_{T} / W U_{*}, 0.416<D_{T} / W U_{*}$ \\
Lau \& Krishnappan (1977) & Straight & Instead of $D_{T} / H U_{* \prime}$ using $D_{T} / W U_{*}$ \\
Webel \& Schatzmann (1984) & Straight & Criticized results of Lau \& Krishnappan (1977) \\
Almquist \& Holley (1985) & Meander & Transverse dispersion coefficient increasing in natural cross section \\
Nokes \& Wood (1988) & Straight & Transverse dispersion coefficient dependent of a friction factor \\
Boxall \& Guymer (2003) & Meander & Conducted with setups natural cross-section \\
Boxall et al. (2003) & Meander & Transverse dispersion coefficient varied in direction of channel \\
& & curvature \\
\hline
\end{tabular}

$D_{L}$ and $D_{T}$ longitudinal \& transverse dispersion coefficients, $H$ water depth, $U_{*}$ shear velocity, $e_{y}$ transverse turbulent diffusivity 
coordinates can be time-averaged and rewritten as three-dimensional advection-diffusion equation.

$$
\frac{\partial s}{\partial t}+v_{x} \frac{\partial s}{\partial x}+v_{y} \frac{\partial s}{\partial y}+v_{z} \frac{\partial s}{\partial z}=e_{m}\left(\frac{\partial^{2} s}{\partial x^{2}}+\frac{\partial^{2} s}{\partial y^{2}}+\frac{\partial^{2} s}{\partial z^{2}}\right)
$$

where $s$ is concentration; $t$ is time; $x, y$, and $z$ is the longitudinal, transverse, and vertical distances measured from the injection point respectively. $v_{x}, v_{y}$, and $v_{z}$ are directional velocities, and $e_{m}$ is the molecular diffusion coefficient. Time averaging three-dimensional advection-diffusion equation can be derived by the Reynolds averaging. And in a mathematical model, the dispersion term is occurred as transforming the three-dimensional advection-diffusion equation into two-dimensional advection-dispersion equation by integration with respect to depth. In rivers, diffusion coefficients are negligible compared to dispersion coefficients with using the continuity equation (Baek 2004).

$$
\frac{\partial C}{\partial t}+u \frac{\partial C}{\partial x}+v \frac{\partial C}{\partial y}=\frac{1}{h} \frac{\partial}{\partial x}\left[h D_{L} \frac{\partial C}{\partial x}\right]+\frac{1}{h} \frac{\partial}{\partial y}\left[h D_{T} \frac{\partial C}{\partial y}\right]
$$

where $D_{L}$ and $D_{T}$ is the longitudinal and transverse dispersion coefficient which accounts for the effects on the depth-averaged tracer concentration of depth variations in the longitudinal and transverse velocity.

Instantaneous injection condition of tracer can be presented with a procedure by Beltaos (1975). Following this suggestion, integrating Eq. 2 with respect to time from $t=0$ to $t=\infty$, gives

$$
\left.C\right|_{\infty}-\left.C\right|_{0}+\int_{0}^{\infty} u \frac{\partial C}{\partial x} d t+\int_{0}^{\infty} v \frac{\partial C}{\partial y} d t=\int_{0}^{\infty} \frac{\partial}{\partial x}\left(D_{L} \frac{\partial C}{\partial x}\right) d t+\int_{0}^{\infty} \frac{\partial}{\partial y}\left(D_{T} \frac{\partial C}{\partial y}\right) d t
$$

Observing $\left.C\right|_{\infty}=\left.C\right|_{0}=0$ for instantaneous injection and introducing the concept of a dosage,

$$
\theta=\int_{0}^{\infty} C d t
$$

Eq. 3 becomes

$$
u \frac{\partial \theta}{\partial x}+v \frac{\partial \theta}{\partial y}=\frac{\partial}{\partial x}\left(D_{L} \frac{\partial \theta}{\partial x}\right)+\frac{\partial}{\partial y}\left(D_{T} \frac{\partial \theta}{\partial y}\right)
$$

The integral equations of conservation of tracer mass are as follows.

$$
\iint_{t} u C d A d t=M(\text { Instantaneous injection })
$$

where $A$ is a cross-sectional area and Eq. 6 can be also re-written as follows with constant injection, $W_{s}$ 


$$
\iint_{A} u \theta d A=W_{S}
$$

With these procedures, the amount of tracer needed to perform an instantaneous test is much less than what is required for a continuous test. And injection of a slug is rather simple whereas constant injection requires special equipment and it may be difficult in rivers with poor accessibility. Additionally an instantaneous test provides information on not only the transverse mixing but also the longitudinal and temporal characteristics. This kind of information is not able to be obtained from a continuous injection condition due to decrease of time variation.

\section{Experimental setup}

Many kinds of researches about mixing in meandering channels have been performed with various channel types and hydraulic conditions changing water supply and water level of downstream. The properties of meander patterns in previous studies are shown in Table 2.

In this study, flow and tracer experiments were conducted in the S-curved meandering laboratory channel with a rectangular cross-section which is $16.5 \mathrm{~m}$ long, $1 \mathrm{~m}$ wide, and $0.6 \mathrm{~m}$ deep. It consists of circular arcs connected by straight sections, as shown in Fig. 3. The radius of curvature of the arc region is $2.0 \mathrm{~m}$, the wavelength is $7.5 \mathrm{~m}$, and the arc angle is $150^{\circ}$ (Park 2008).

Velocity data and solute concentration was measured by micro-ADV (Acoustic Doppler Velocimetry) and the electrode conductivity meter (KENEK: Model NST-30) respectively. The density of the salt solution was adjusted to that of the flume water by adding methanol. The tracer material can be instantaneously injected into water flow as a full-depth vertical line source by using the injecting acrylic cylinder. The initial concentration of the tracer was $100,000 \mathrm{mg} / \ell$. The interval of concentration measuring points at each section was about $7 \mathrm{~cm}$ in the transverse direction. Four cases of tracer tests have been proposed and performed in this test. The tracer was instantaneously injected into the flow as a full-depth vertical line source either at the centerline of the channel. Vertically, at a point located $60 \%$ of the water depth above the bottom, concentration was measured under the shallow water cases $(H=15,20 \mathrm{~cm})$. And at two points located 20,80\% of the water depth above the channel bottom, concentration was measured under the deep water cases $(\mathrm{H}=30,40 \mathrm{~cm})$.

Table 2 Properties of Meander Pattern of Previous Studies and This Research

\begin{tabular}{llllll}
\hline Researcher & $R_{C} N$ & $\varphi^{\circ}$ W & $\lambda / W$ & $\lambda / R_{C}$ & Sinuosity \\
\hline Leopold and Wolman (1960) & 2.3 & - & 10.9 & 4.7 & - \\
Chang (1971) & 3.6 & 90 & - & - & 1.11 \\
Krishnappan and Lau (1977) & $0.6 \sim 2.2$ & - & 6.3 & $3 \sim 10.8$ & - \\
Almquist and IHolley (1985) & 3 & 125 & 12 & 4 & 1.30 \\
Guymer (1998) & 3.5 & 120 & 13.7 & 3.9 & 1.21 \\
Jeong (2004) & 2.4 & 120 & 9.7 & 4 & 1.32 \\
This study & 2.0 & 150 & 7.5 & 3.8 & 1.52 \\
\hline
\end{tabular}

$R_{C} / \mathrm{W}$ radius of curvature, $\lambda$ wavelength, $\phi$ : degree of channel meander 


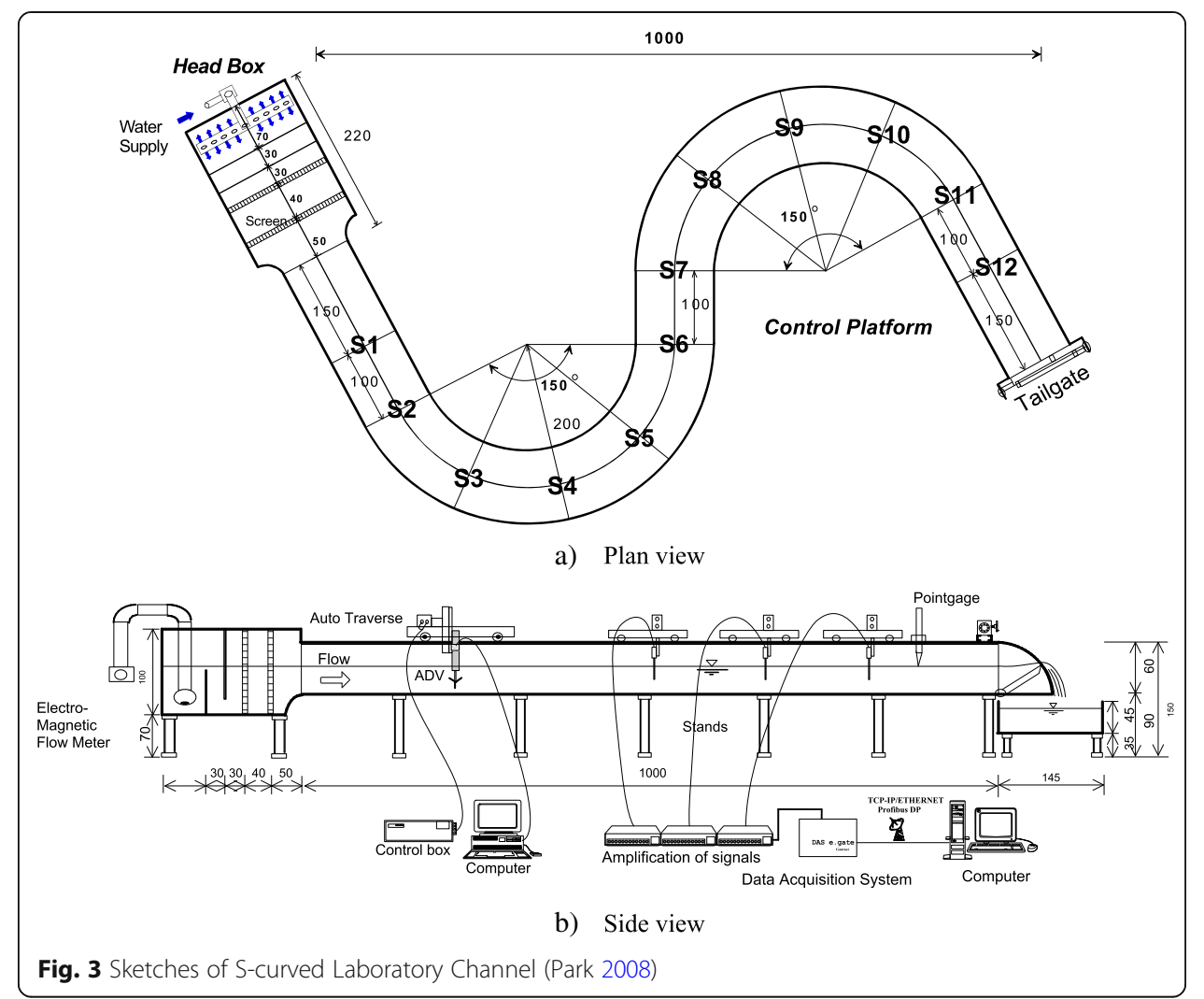

\section{Numerical analysis}

\section{Flow models}

RMA-2 is the two-dimensional depth-averaged finite element hydrodynamic model of commercial software SMS (Surface-water modeling system. It computes a finite element solution of the Reynolds form of the Navier-Stokes equations for turbulent flow. Friction is calculated with the Manning's or Chezy equation, and eddy viscosity coefficients are used to define turbulent characteristics. In this model, both steady and unsteady state problems can be simulated. The generalized computer program RMA-2 solves the depth-integrated equations of fluid mass and momentum conservation in two horizontal directions. The forms of governing equations are like follows

$$
\begin{aligned}
& h \frac{\partial u}{\partial t}+h u \frac{\partial u}{\partial x}+h v \frac{\partial u}{\partial y}-\frac{h}{\rho}\left(E_{x x} \frac{\partial^{2} u}{\partial x^{2}}+E_{x y} \frac{\partial^{2} u}{\partial y^{2}}\right)+g h\left(\frac{\partial b}{\partial x}+\frac{\partial h}{\partial x}\right)+\frac{g u n^{2}}{h^{1 / 3}} U-\zeta V_{a}^{2} \cos \psi-2 h \omega v \sin \phi_{l}=0 \\
& h \frac{\partial v}{\partial t}+h u \frac{\partial v}{\partial x}+h v \frac{\partial v}{\partial y}-\frac{h}{\rho}\left(E_{y x} \frac{\partial^{2} v}{\partial x^{2}}+E_{y y} \frac{\partial^{2} v}{\partial y^{2}}\right)+g h\left(\frac{\partial b}{\partial y}+\frac{\partial h}{\partial y}\right)+\frac{g v n^{2}}{h^{1 / 3}} U-\zeta V_{a}^{2} \sin \psi+2 h \omega v \sin \phi_{l}=0 \\
& \frac{\partial h}{\partial t}+h\left(\frac{\partial u}{\partial x}+\frac{\partial v}{\partial y}\right)+u \frac{\partial h}{\partial x}+v \frac{\partial h}{\partial y}=0
\end{aligned}
$$

where $\rho$ is density of fluid, $E_{x x}$ is eddy viscosity coefficient for normal direction on $x$ axis surface, $E_{y y}$ is for normal direction on $y$ axis surface, $E_{x y}$ and $E_{y x}$ is for 
shear direction on each surface, $g$ is acceleration due to gravity, $b$ is elevation of bottom, $n$ is roughness coefficient in Manning's formula, $\zeta$ is empirical wind shear coefficient, $V_{a}$ is wind speed, $\omega$ is rate of earth's angular rotation, and $\phi_{l}$ is local latitude.

RAMS (River Analysis and Modeling System) is consist of river flow analysis model (RAM2), pollutant transport model (RAM4), bed elevation change model (RAM6), and graphic user interface (RAMS-GUI) is combined with above numerical programs to develop commercial package. This software can simulate physical phenomena in natural rivers with complex topography by 2D finite element numerical calculations with underlying consistency and generality, which would provide accurate and stable solutions to open channel flow equation, and mass transport equation for various types of problems.

Flow model, RAM2 is a finite element model based on Streamline Upwind / Petrov-Galerkin (SU/PG) scheme for analyzing and simulating two-dimensional flow characteristics of irregular natural rivers with complex geometries. The type of elements in a mesh can be a triangular, quadrilateral or mixed one. A triangular element could have either 3-nodes or 6-nodes and a quadrilateral element either 4-nodes or 8-nodes. This mesh can constructed from DEM and TIN format in the tools of GIS.

$$
\begin{aligned}
& \frac{\partial h}{\partial t}+\frac{\partial(u h)}{\partial x}+\frac{\partial(v h)}{\partial y}+i=0 \\
& \frac{\partial(u h)}{\partial t}+\frac{\partial\left(u^{2} h\right)}{\partial x}+\frac{\partial(u v h)}{\partial y}+g \frac{\partial\left(h^{2} / 2 a\right)}{\partial x}=g h\left(S_{a x}-S_{f x}\right) \\
& \frac{\partial(v h)}{\partial t}+\frac{\partial\left(v^{2} h\right)}{\partial y}+\frac{\partial(u v h)}{\partial x}+g \frac{\partial\left(h^{2} / 2 a\right)}{\partial y}=g h\left(S_{a y}-S_{f y}\right)
\end{aligned}
$$

\section{Pollutant transport models}

RAM4 is a FEM model for pollutant transport analysis in two-dimensional flow fields and it is developed based on the depth-averaged mass transport equation. It can calculate the advection and dispersion of injected substances in a two-dimensional flow field. This engine can treat the conservative or non-conservative substances as pollutant tracers. The advection-diffusion equation is a very common mathematical model that is generally used to simulate mass transport in the flow of some fluids. Its general expression can be written as:

$$
\frac{\partial c}{\partial t}+\nabla \cdot(\mathrm{q} c)-\nabla \cdot(\mathrm{D} \cdot \nabla c)=0, \mathrm{x} \in \Omega, t \in[0, T]
$$

where $x$ and $t$ are space and time variable respectively, $c$ is unknown variable which denotes solute concentration in this model, q the fluid velocity vector, and $\mathrm{D}$ the diffusion/dispersion tensor, $\Omega$ a bounded problem domain in 2D or 3D space, and $T$ is objective time defined in the problem. Three types of boundary conditions can be defined for the problem domains. The first type can be defined on a boundary segment. 
The governing equation modeled in RAM4 is a $2 \mathrm{D}$ advection-dispersion equation which is given as

$$
\begin{array}{r}
\frac{\partial(h C)}{\partial t}+\frac{\partial(u h C)}{\partial x}+\frac{\partial(\nu C)}{\partial y}-\frac{\partial}{\partial x}\left[h\left(D_{x x} \frac{\partial C}{\partial x}+D_{x y} \frac{\partial C}{\partial y}\right)\right]-\frac{\partial}{\partial y}\left[h\left(D_{y x} \frac{\partial C}{\partial x}+D_{y y} \frac{\partial C}{\partial y}\right)\right] \\
+k h C=Q
\end{array}
$$

where is the first order decay coefficient and is some sink or source function. From researches about equations of tensor-forming dispersion coefficients (Fischer 1979; Alavian 1986) by applying Taylor's method to a 2D advection-dispersion model, the following dispersion coefficient tensor forms can represent the longitudinal and transverse dispersion coefficients of the curved channel in fixed Cartesian coordinate system.

$$
\begin{aligned}
& D_{x x}=D_{L} \frac{u^{2}}{U^{2}}+D_{T} \frac{v^{2}}{U^{2}} \\
& D_{x y}=D_{y x}=\left(D_{L}-D_{T}\right) \frac{u v}{U^{2}} \\
& D_{y y}=D_{T} \frac{u^{2}}{U^{2}}+D_{L} \frac{v^{2}}{U^{2}}
\end{aligned}
$$

The SUPG (Streamline-Upwind/ Petrov - Galerkin) method with finite difference time discretization was used for the finite element formulation of RAM4. When the advective transport is dominant compared with dispersive transport, numerical solutions by conventional numerical methods exhibit excessive nonphysical oscillation or artificial smearing. SUPG method can overcome the generally well-known numerical errors in the modeling of advection dominated conditions.

\section{Results and analysis}

\section{Primary flow}

\section{Observed data}

Velocity data detected in this S-curved channel are expressed with two-dimensional vector profiles and contour maps at the test sections (S1 S12). Transverse distribution of the primary velocity skews toward the inner bank at the bends and at the crossovers, almost symmetric. Additionally, maximum velocities in each transverse sections, has been detected taking the shortest course. The reason of this discrepancy in the flow pattern is that experiments were conducted on the rectangular cross-section channel, whereas, the cross-sectional shape of the natural stream is usually triangular, and skewed to the outer bank with fixed or mobile beds. This means that the main flow moves along the shortest path of the meandering channel. This phenomenon is contrary to the fact that the main stream biases to the outer side of the curve at the curve of the natural rivers or streams. It is analyzed that the cross section of the meandering channel used in this experiment is rectangular and the roughness (painted steel) of the channel is different from the natural river Fig. 4. 
a) $Q=30$ liters $/ \mathrm{sec}$., $h=\mathbf{2 0} \mathrm{cm}$

S9 S10

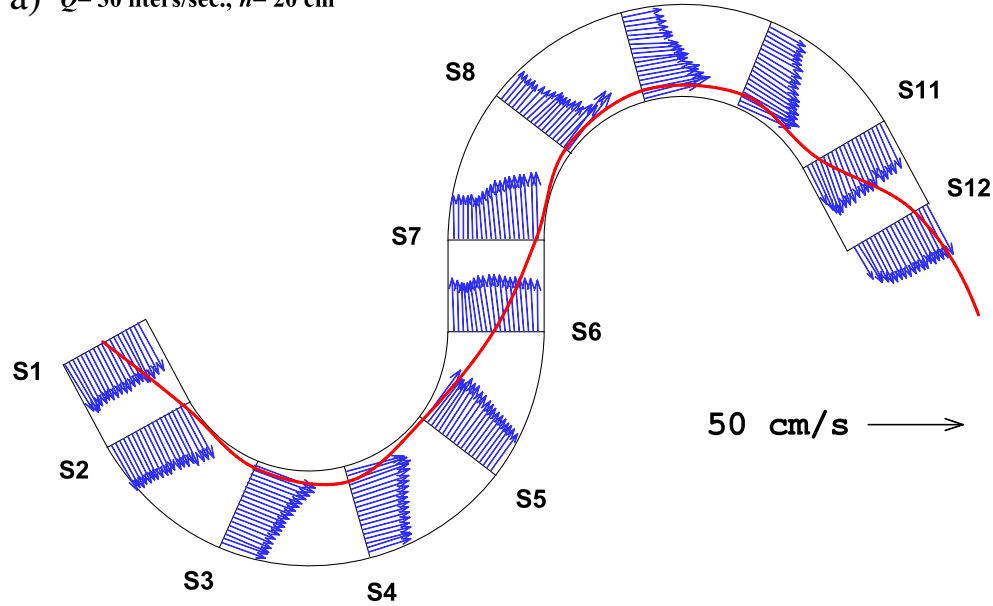

b) $Q=\mathbf{3 0}$ liters $/ \mathrm{sec}$, $h=\mathbf{3 0} \mathrm{cm}$

s1

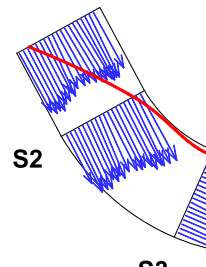

S3
S7

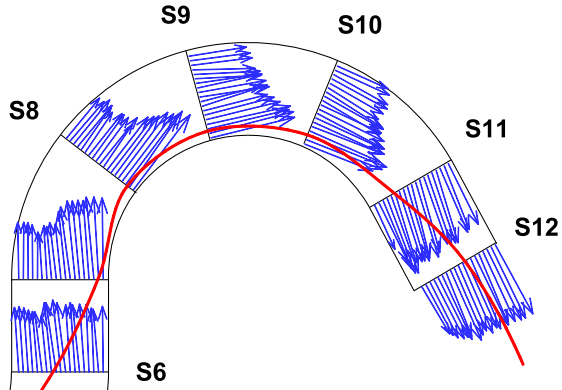

$30 \mathrm{~cm} / \mathrm{s}$

Fig. 4 Vector maps of primary velocity profiles (left: Case B202; right: Case B302)

\section{Simulated data}

Contour distribution of two-dimensional primary velocities is a little different from observed data. But its ranges from maximum to minimum values of primary velocities are almost same as experimental data (Fig. 5, Table 3).

As following figures, both of models have a good fitting on the experimental data in the apex of two meanders. However, RMA-2 model overestimates the experimental result while RAM2 model underestimates it (Fig. 6). In Fig. 7, experimental data and results of two models were plotted and compared. Differences near the inlet and outlet were smaller than those near the main channel. Entirely, simulated data with RAM2 is closer to the experimental data than simulated data with RMA-2 which is overestimated (Fig. 8).

\section{Tracer transport}

\section{Observed data}

Tracer tests in this $\mathrm{S}$-curved channel, the concentration $(\mathrm{H}=30 \mathrm{~cm}, \mathrm{Q}=30 \mathrm{l} / \mathrm{sec})$. All concentration data were filtered by the moving average to reduce the 

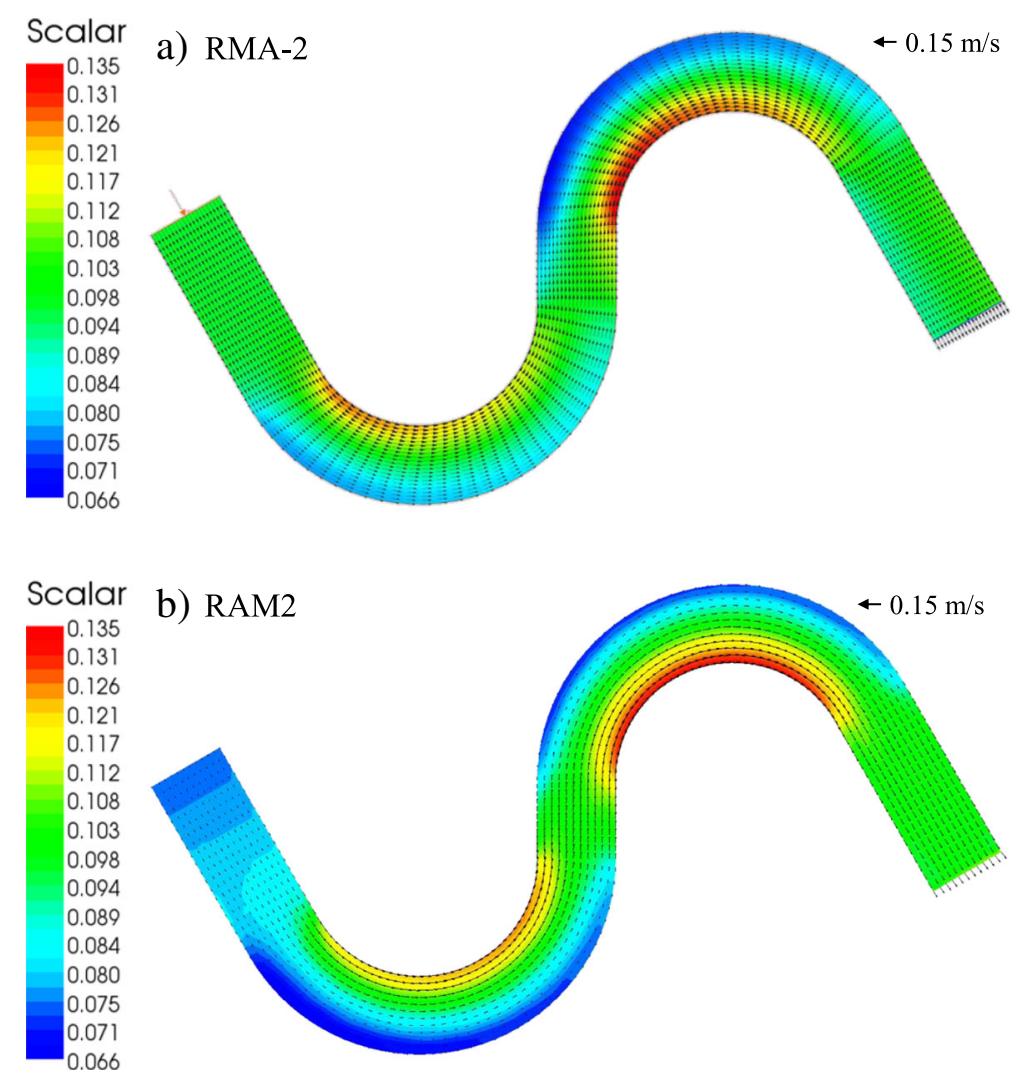

b) RAM2

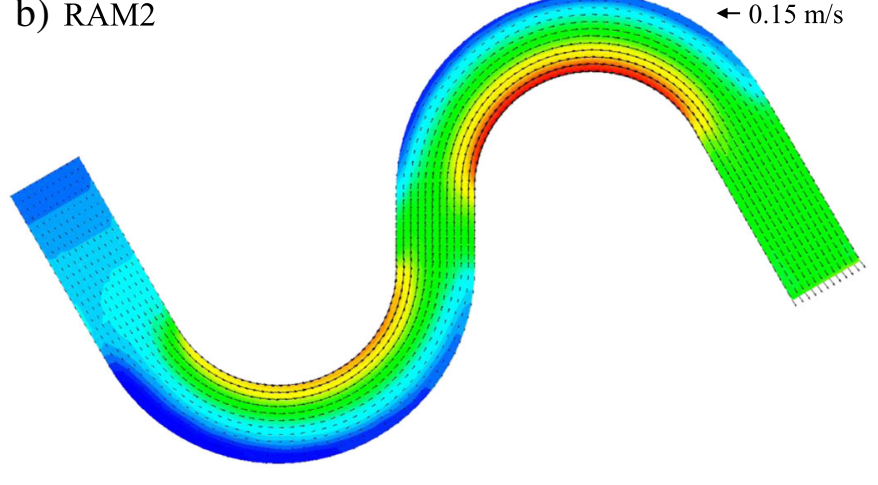

Fig. 5 Simulated vector maps of velocity profiles

mechanical noise. Passing the crossover, high concentration is detected near the right bank. The duration of the tracer detection is longer than others, and multiple peaks are frequently observed. In order to visualize the behavior of the tracer clouds, the spatial contours, which are made by the interpolation technique through the concentration-time data, are plotted in Fig. 9. From the observed data, specific behaviors can be founded; the first bend region with relatively little secondary current effect and the second bend region which was divided again into entrance, apex, and exit. Asymmetry velocity profiles can make spatial re-arrangements of pollutant clouds with regional stabilities (Seo and Park 2009). Through the first meandering apex, the pollutant cloud is separated in the channel width direction under the influence of the horizontal two-dimensional flow velocity distribution. This is because relatively slow flow velocity occurs at the right bank of the first curve and relatively fast flow occurs at the left bank. This phenomenon appears to be somewhat reduced while encountering the straight-connection part, but it reappears as it enters the second curve. In addition, the pollutant cloud itself is formed longer. That is, the tail part of the pollutant cloud

Table 3 Properties of geometries for simulation (SMS and RAMS)

\begin{tabular}{lll}
\hline & RMA-2 & RAM2 \\
\hline Number of nodes & 7729 & 2625 \\
Number of element & 2480 & 2480 \\
Element type & Rectangular (quadratic basis element) & Rectangular (linear basis element) \\
\hline
\end{tabular}




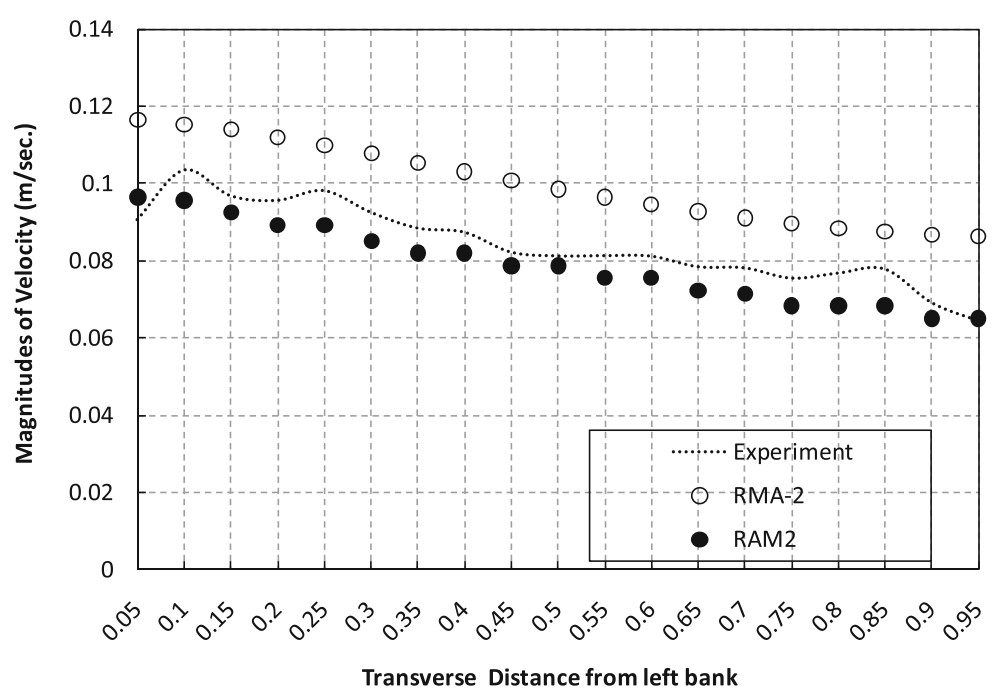

a) At the first meander (S4)

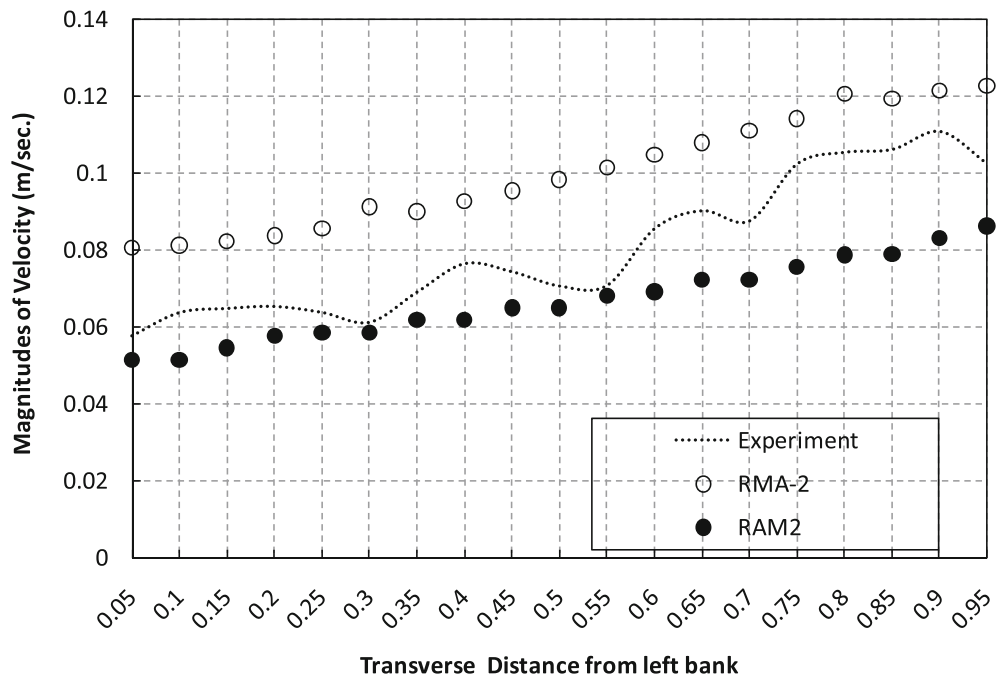

b) At the second meander (S9)

Fig. 6 Comparison of flow velocity at the apex

develops longer as the flow velocity deviation between the left and right banks of the channel is decreased at the straight connection part. This occurs when the pollutant cloud enters the apex of the second meandering part and exits the canal with the opposite of the first meandering apex. Thus, it was revealed that the various patterns of pollutant transport are dominantly influenced on the flow velocity distribution along meandering channel.

\section{Simulated data}

With pollutant transport models, four pollutant distributions for each model were plotted in Figs. 10 and 11. Two set of them have same patterns of experimental data about pollutant transport. However, simulated results of RMA-4 from $25 \mathrm{~s}$ to $35 \mathrm{~s}$ were a little different from experimental data. Especially transverse mixing with RMA-4 is smaller 


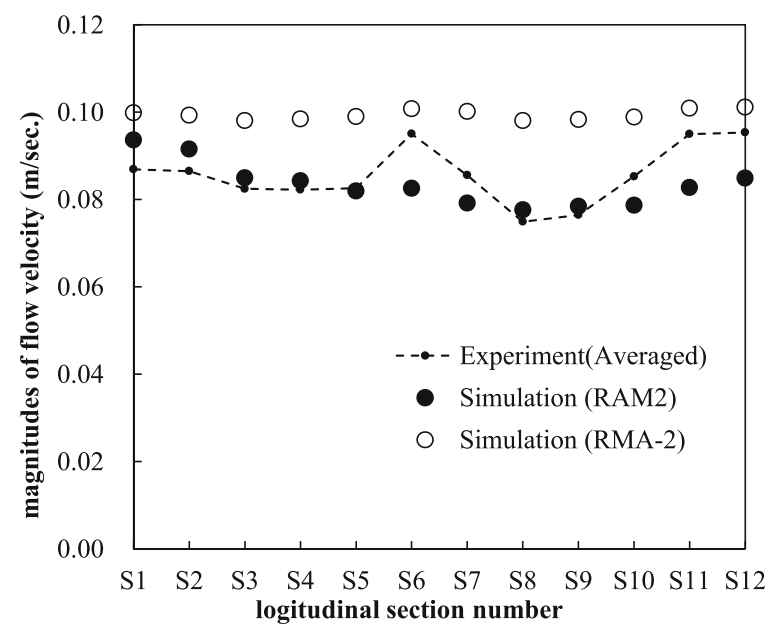

Fig. 7 Comparison primary flow along the longitudinal section

than experimental data. While simulated results with using RAM4 have same pattern of experimental data and longitudinal and transverse mixing were same qualitatively.

\section{Conclusions}

In this research, velocity profiles of experiment method and numerical simulation have been com-pared and analyzed with same hydraulic conditions. The depth-averaged primary velocity vector field of the representative case was plotted in Fig. 10. As shown in this figure, the velocity distribution of the primary flow for all cases skewed toward the inner bank at the first bend, and was almost symmetric at the crossovers, and then shifted toward the inner bank again at the next alternating bend. Thus, one can clearly notice that the maximum velocity occurs taking the shortest course along the channel, irrespective of the flow conditions. This behavior of the primary flow in meandering channels with a rectangular cross-section was reported by several researchers (Chang 1971; Almquist and

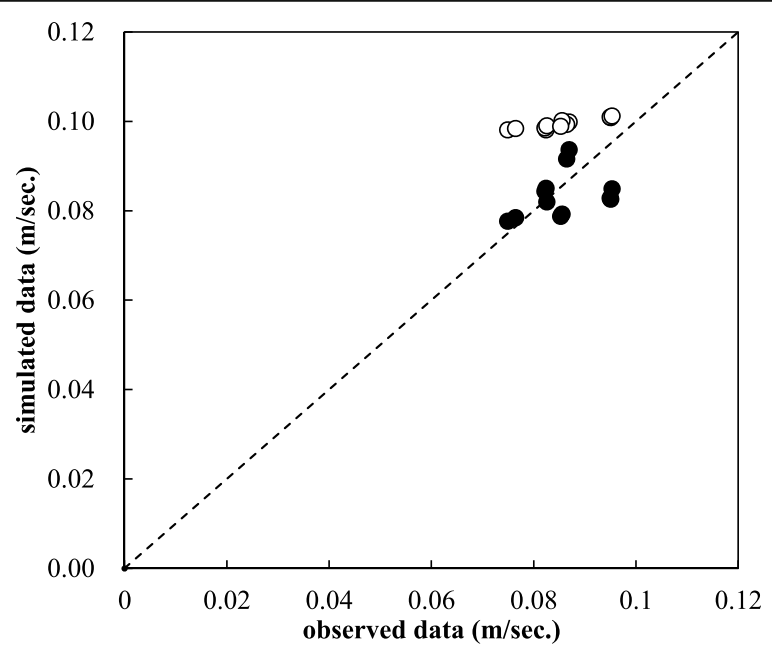

Fig. 8 Comparison of flow results 

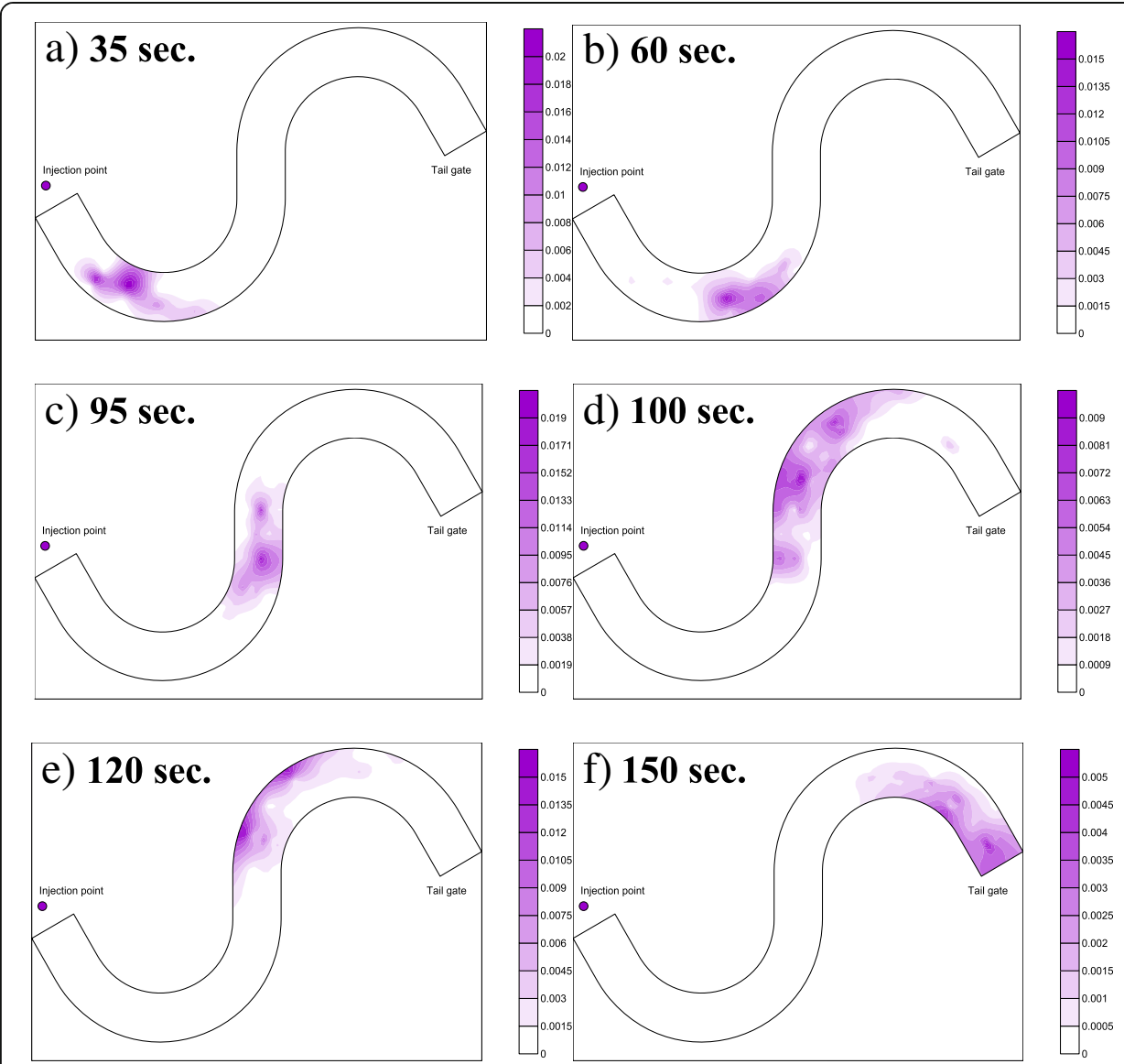

Fig. 9 Contours maps of observed solute transport

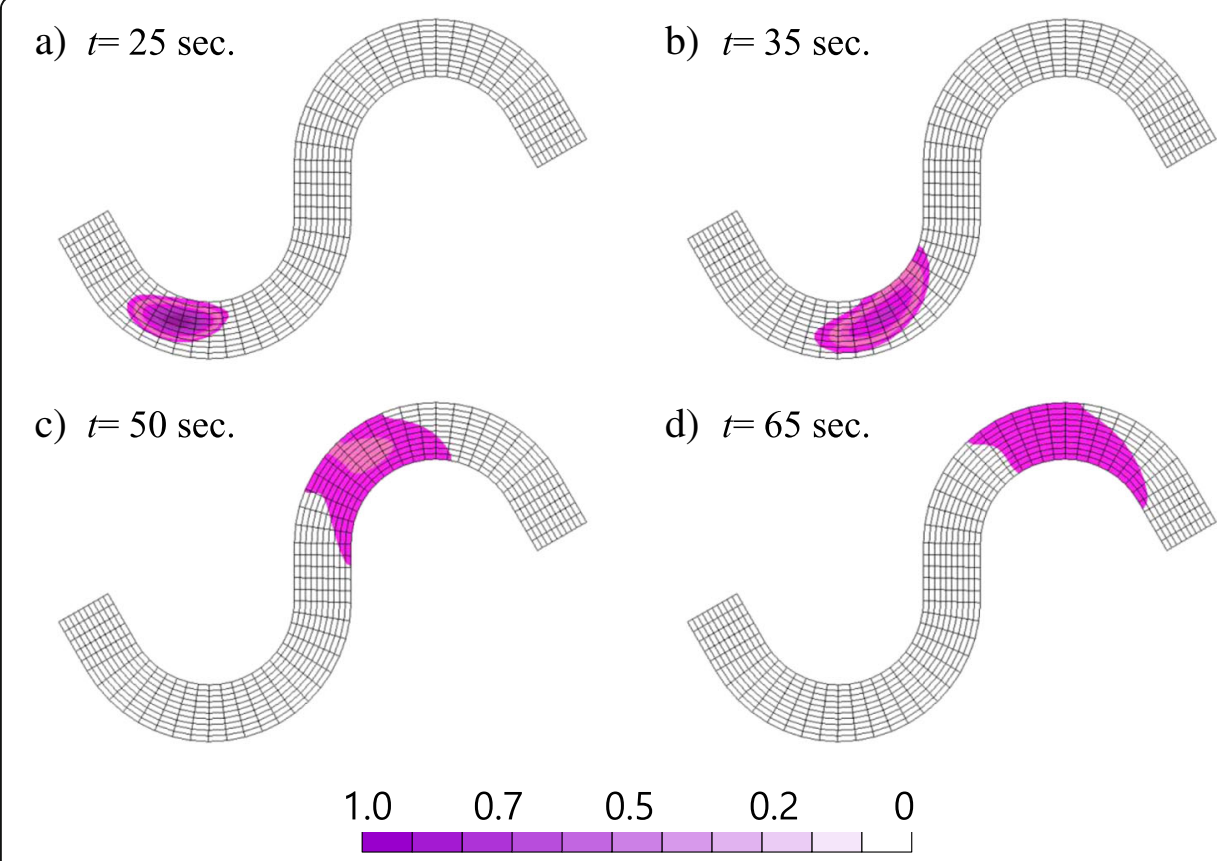

Fig. 10 Simulated results of pollutant transport with RMA-4 


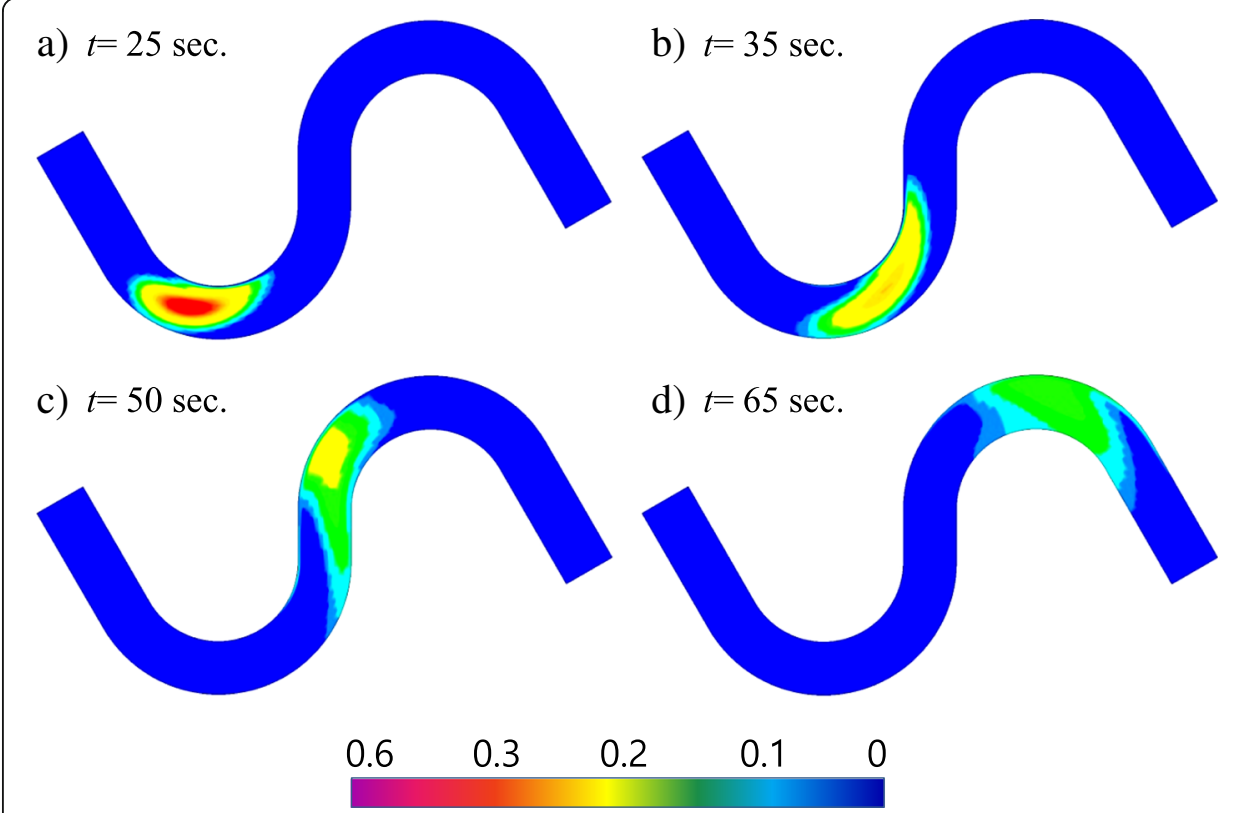

Fig. 11 Simulated results of pollutant transport RAM4

Holley 1985; Shiono and Muto 1998). The result of the tracer tests shows that pollutant clouds are spreading following the maximum velocity lines in each case.

Secondly, several various characteristics were expressed by velocity structures such as the secondary flow, shear flow, and path of primary flow. Separation and stagnation have been occurred from asymmetric velocity fields. As velocity increases, superposition and secondary separation of concentration cloud repeatedly occur with progressive movements.

Furthermore numerical simulation data can make expectation of the similar developments such as separation, stagnation, and superposition of pollutant clouds. In the future, characteristics of solute transport in the channel can be compared with 2-D numerical analysis using quantitative analysis methods of plotting. For the longitudinal progress, transverse spatial distribution, and dimensional hydraulic index can be estimated with the further researches.

Acknowledgments

This work was supported by National Research Foundation of Korea (NRF) grant funded by Korean government Ministry of Science, ICT \& Future Planning 2016R1C1B1014280.

Funding

This work was supported by National Research Foundation of Korea (NRF) grant funded by Korean government Ministry of Science, ICT \& Future Planning 2016R1C1B1014280.

Availability of data and materials

Not applicable, because this paper is not Biological nor Medical.

Authors' contributions

The first author performed modeling works and the second author finalized the results. The figures were prepared by the first author and the manuscript was written by both authors. Both authors read and approved the final manuscript. 


\section{Publisher's Note}

Springer Nature remains neutral with regard to jurisdictional claims in published maps and institutional affiliations.

Received: 3 September 2018 Accepted: 17 April 2019

Published online: 10 May 2019

\section{References}

Alavian V (1986) Dispersion tensor in rotating flows. J Hydr Eng 112(8):771-777

Almquist CW, Holley ER (1985) Transverse mixing in meandering laboratory channels with rectangular and naturally varying cross sections. In: Technical Report CRWR-205. University of Texas, Austin

Baek KO (2004) Transverse Mixing in Meandering Channels with Unsteady Pollutant Source. Ph.D. Thesis, Seoul National University in South Korea

Beltaos S (1975) Evauation of transverse mixing coefficients from slug tests. J Hydr Res 13(4):351-360

Boxall JB, Guymer I (2003) Analysis and prediction of transverse mixing coefficients in natural channels. J Hydr Eng 129(2): 129-139

Chang Y (1971) Lateral mixing in meandering channels. Ph.D. Thesis, Univ. of lowa, lowa City

Duan G (2004) Simulation of flow and mass dispersion in meandering channels. J Hydr Eng 130(10):964-976

Elder JW (1959) The dispersion of marked fluid particles in turbulent shear flow. J Fluid Mech 5(4):544-560

Fischer HB (1969) The effect of bends on dispersion in streams. Water Resour Res 5(2):496-506

Fischer HB, List EJ, Koh Robert CY, Imberger J, Brooks NH (1979) Mixing in Inland and Coastal Waters

Guymer I (1998) Longitudinal dispersion in sinuous channel with changes in shapes. J Hydr Engrg 124(1):33-40

Jeong SJ (2004) Experimental investigation of transverse mixing of pollutants in meandering channels. MS. D. Thesis, Seoul National University in South Korea (in Korean)

Kim HJ (2006) Investigation on Initial Mixing of Pollutants in Rivers. MS. D. Thesis, Seoul National University in South Korea

Krishnappan BG, Lau YL (1977) Transverse mixing in meandering channels with varying bottom topography. J Hydr Res 15(4): 351-371

Lau YL, Krishnappan BG (1977) Transverse dispersion in rectangular channel. J Hydr Div 103(HY10):1173-1189 Leopold LB, Wolman MG (1960) River meanders. Bull Geol Soc Am 71:769-794

McGuirk JJ, Rodi W (1978) A depth-averaged mathematical model for the near field of side discharges into open channel flow. J Fluid Mech 86(4):761-781

Miller AC, Richardson EV (1974) Diffusion and dispersion in open channel flow. J Hydr Div 100(1):159-171

Nokes RI, Wood IR (1988) Vertical and lateral turbulent dispersion: Some experimental results. J Fluid Mech 187:373-394

Park SW (2008) Effects of Velocity Distributions on Tracer Dispersion Coefficient in a Meandering Channel. MS. D. thesis, Seoul National University in South Korea (in Korean)

Rozovskii IL (1961) Flow of water in bends of open channels. Israel Program for Scientific Translation, Jerusalem (published in Russian, 1957)

Seo IW, Park SW (2009) Effects of velocity structures on tracer mixing in a Meandering Channel. J KSCE 29(1):35-45 in Korean Shiono K, Muto Y (1988) Complex flow mechanisms in compound meandering channels with overbank flow. J Fluid Mech $376: 221-261$

Webel G, Schatzmann M (1984) Transverse mixing in open channel flow. J Hydr Eng 110(4):423-435

\section{Submit your manuscript to a SpringerOpen ${ }^{\circ}$ journal and benefit from:}

- Convenient online submission

Rigorous peer review

- Open access: articles freely available online

- High visibility within the field

- Retaining the copyright to your article

Submit your next manuscript at $\boldsymbol{\nabla}$ springeropen.com 